\title{
A morphometric study of the lumbar spinous process in the Chinese population
}

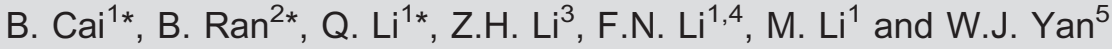 \\ ${ }^{1}$ Department of Orthopedics, Changhai Hospital Affiliated to the Second Military Medical University, Shanghai, China \\ ${ }^{2}$ Department of Orthopedics, First Affiliated Hospital of Xuzhou Medical University, Xuzhou, China \\ ${ }^{3}$ Department of Orthopedics, First Affiliated Hospital of PLA General Hospital, Beijing, China \\ ${ }^{4}$ Third Affiliated Hospital of Second Military Medical University, Shanghai, China \\ ${ }^{5}$ Department of Orthopedic Oncology, Changzheng Hospital, The Second Military Medical University, Shanghai, China
}

\begin{abstract}
Our goal was to analyze the anatomical parameters of the lumbar spine spinous process for an interspinous stabilization device designed for the Chinese population and to offer an anatomical basis for its clinical application. The posterior lumbar spines $\left(T_{12}-S_{1}\right)$ of 52 adult cadavers were used for measuring the following: distance between two adjacent spinous processes (DB), distance across two adjacent spinous processes (DA), thickness of the central spinous processes (TC), thickness of the superior margin of the spinous processes (TS), thickness of the inferior margin of the spinous processes ( $\mathrm{TI}$ ), and height of the spinous processes $(\mathrm{H})$. Variance and correlation analyses were conducted for these data, and the data met the normal distribution and homogeneity of variance. DB decreased gradually from $L_{1-2}$ to $L_{5}-S_{1}$. DA increased from $T_{12}-L_{1}$ to $L_{2-3}$ and then decreased from $L_{2-3}$ to $L_{4-5}$. The largest $H$ in males was noted at $L_{3}(25.45 \pm 5.96 \mathrm{~mm})$, whereas for females the largest $H$ was noted at $\mathrm{L}_{4}(18.71 \pm 4.50 \mathrm{~mm})$. Usually, TS of the adjacent spinous process was lower than TI. Based on the anatomical parameters of the lumbar spinous processes obtained in this study, an "H"-shaped coronal plane (posterior view) was proposed as an interspinous stabilization device for the Chinese population. This study reports morphometric data of the lumbar spinous processes in the Chinese population, which provides an anatomical basis for future clinical applications.
\end{abstract}

Key words: Lumbar spine; Morphometry; Spinal stenosis; Spinous process

\section{Introduction}

Lumbar spinal stenosis comprises a narrowing of the spinal canal, with subsequent neural compression, and is frequently associated with symptoms of neurogenic claudication. This condition occurs as a result of age-related spinal degeneration, particularly in the intervertebral disc and ligamentum flavum. Patients who exhibit mild to moderate symptoms of lumbar spinal stenosis should undergo multimodal conservative treatment. In patients with severe symptoms, decompression surgery is indicated if conservative treatment proves ineffective after 3-6 months (1-3). However, there are some drawbacks with surgical treatments, such as secondary instability and back pain in laminectomy without fusion, and a considerable amount of morbidity and complication in rigid arthrodesis (3-5).

Recently, there has been an increased popularity of the procedure of nonfusion stabilization of the lumbar spine, which maintains or restores intersegmental motion to the magnitude of the intact spine and has no negative effects on the segments adjacent to the stabilized one (6). A biomechanical study of an interspinous stabilization spinal implant indicates that it offers nonrigid fixation and can return a partially destabilized specimen back to the intact condition in terms of motion in flexion/extension and axial rotation (7). Another biomechanical evaluation of an interspinous stabilizing device called a "locker" indicates that such a locker shows a significant stabilizing effect on the spinal motion segment both in the intact and destabilized spine, without any significant effect on adjacent segments (8). Dynamic stabilization using interspinous implants is less invasive in terms of its simple surgical procedure and the shorter operation time, and it can modify surgical procedures (2). Nevertheless, complications may also occur in interspinous implants such as implant migration and spinous fracture (9-11). Establishing clear indications and developing

Correspondence: Ming Li <liiming@hotmail.com>; Wangjun Yan <yanwangjjun@163.com>.

${ }^{*}$ These authors contributed equally to this study.

Received May 30, 2014. Accepted July 24, 2014. First published online October 24, 2014. 
sophisticated implants may prevent these complications $(2,11)$. Therefore, it is important to clarify the exact anatomy of the spinous process and provide a snugly fitting device.

To our knowledge, there have been few reports of spinous process morphometry in the Chinese population. In the present work, the anatomical parameters of the lumbar spine spinous process were measured, for the purpose of designing interspinous stabilization devices for the Chinese population. The results of this study will be helpful by offering an anatomical basis for clinical applications.

\section{Material and Methods}

\section{Material}

A total of 52 adult cadavers were used. The study group comprised 30 men and 22 women. Exclusion criteria included pathological changes such as congenital vertebral anomalies, trauma, tumors, and sacralization. For inclusion of cadavers in the study, written informed consent was obtained from family members or legal guardians. In addition, all human studies were approved by the China Ethics Committee and performed in accordance with its ethical standards.

\section{A}
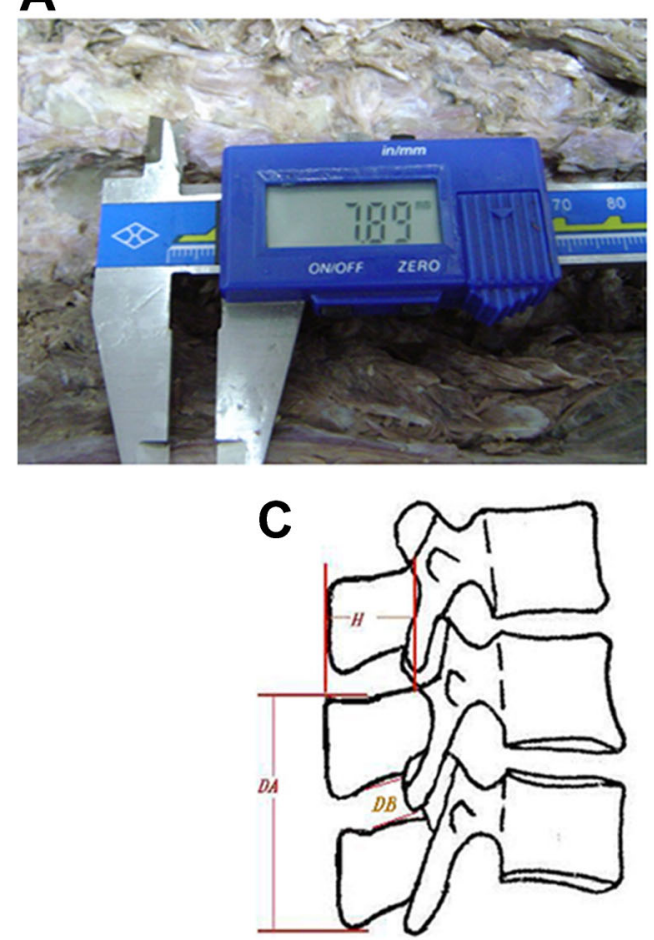

\section{Measuring parameters}

The cadavers were placed in a prone position for numbering the vertebra. The posterior lumbar spine $\left(T_{12}-\right.$ $\mathrm{S}_{1}$ ) was exposed, and the spinous process, vertebral plate, and articular process were revealed (Figure 1A and B). A digital caliper was used for measurement. Three measurements were made for each distance. The main measuring parameters were as follows (Figure 1C): 1) distance between the two adjacent spinous processes (DB), $L_{1-2}$, $L_{2-3}, L_{3-4}, L_{4-5}$, and $L_{5}-S_{1}$ were determined; 2) distance across the two adjacent spinous processes (DA), $T_{12}-L_{1}$, $L_{1-2}, L_{2-3}, L_{3-4}$, and $L_{4-5}$ were measured; 3 ) thickness of the central spinous processes (TC); 4) thickness of the superior margin of the spinous processes (TS), $L_{2}, L_{3}, L_{4}, L_{5}$, and $S_{1}$ were measured; 5) thickness of the inferior margin of the spinous processes ( $\mathrm{TI}), \mathrm{L}_{1}-\mathrm{L}_{5}$ were measured; and 6) height of spinous processes $(H), L_{1}-L_{5}$ were measured.

\section{Statistical analysis}

The results are reported as means $\pm \mathrm{SD}$. $\mathrm{P}<0.05$ was considered to be statistically significant. Statistical evaluation was performed using the SPSS version 12.0 software (SPSS Inc., USA). One-sample Kolmogorov-Smirnov test and one-way analysis of variance were used to evaluate the

\section{B}
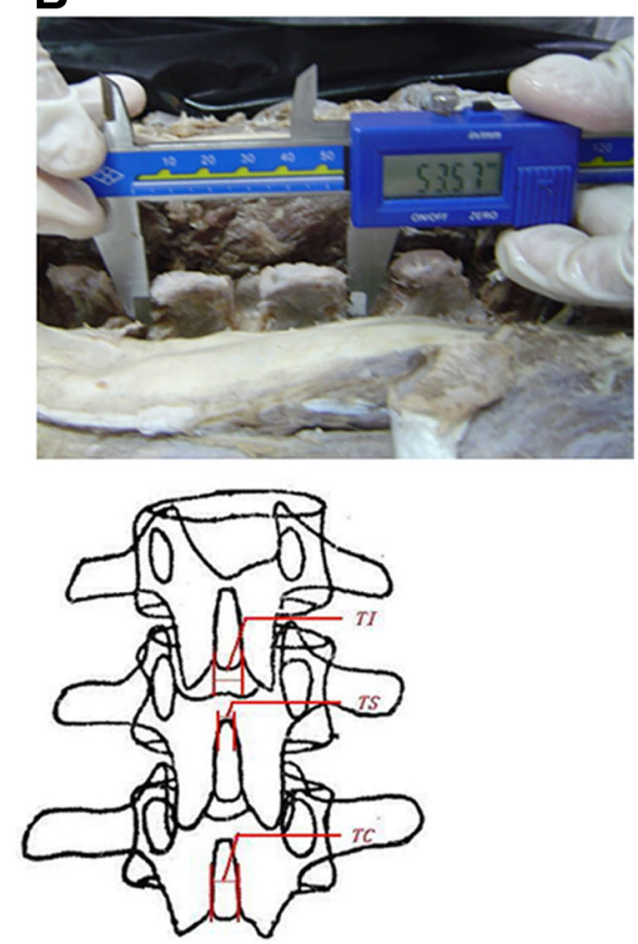

Figure 1. Illustration of measuring method for each parameter. $A$, Measurement of $D B ; B$, measurement of DA; $C$, schematic diagram of H, DA, DB, TI, TS, and TC. H: height of the spinous processes; DA: distance across two adjacent spinous processes; DB: distance between two adjacent spinous processes; TI: thickness of the inferior margin of the spinous processes; TS: thickness of the superior margin of the spinous processes; TC: thickness of the central spinous processes. 
normal distribution and the homogeneity of variance among data. The influence of gender on the interspinous distance was analyzed using Pearson's correlation analysis.

\section{Results}

\section{Statistics}

A one-sample Kolmogorov-Smirnov test confirmed the approximately normal distribution among data in each group, and one-way analysis of variance indicated the homogeneity of variance among data in each group. There were no statistically significant differences among TC and $\mathrm{TI}$ in males and TC, TI, and $\mathrm{H}$ in females by variance analysis, respectively (Table 1 ).

\section{Anatomical parameters of the lumbar spine spinous process}

The anatomical parameters of the lumbar spine spinous process in males and females indicated a similar variation trend (Figure 2). The DB decreased gradually from $L_{1-2}(7.61 \pm 2.44 \mathrm{~mm})$ to $L_{5}-S_{1}(4.03 \pm 2.57 \mathrm{~mm})$. The DA increased from $T_{12}-L_{1}(54.63 \pm 6.50 \mathrm{~mm})$ to $L_{2-3}$ $(60.18 \pm 6.11 \mathrm{~mm})$, then decreased from $L_{2-3}$ to $L_{4-5}$ $(45.07 \pm 5.89 \mathrm{~mm})$. The largest $\mathrm{H}$ in males was noted at $\mathrm{L}_{3}(25.45 \pm 5.96 \mathrm{~mm})$, while it was noted at $L_{4}$ $(18.71 \pm 4.50 \mathrm{~mm})$ in females. Usually, the TS values for the adjacent spinous processes were lower than the $\mathrm{TI}$ values. For example, the TS of $L_{2}(5.97 \pm 2.11 \mathrm{~mm})$ was lower than the $\mathrm{TI}$ of $\mathrm{L}_{1}(8.42 \pm 1.52 \mathrm{~mm})$, and the TS of $L_{3}(6.12 \pm 1.89 \mathrm{~mm})$ was lower than the $\mathrm{TI}$ of $L_{2}$ $(9.57 \pm 2.63 \mathrm{~mm})$.

Comparisons of each parameter between males and females are shown in Figure 2. The DB values showed no statistically significant difference between males and females. There was, however, a statistically significant difference between the DA of males and females, except for $L_{4-5}$. The TS of $L_{2}$ and $L_{3}$ showed a statistically significant difference between males and females, and the other segments did not. Except for $L_{5}$, there was a statistically significant difference in the $\mathrm{TI}$ of $\mathrm{L}_{1}-\mathrm{L}_{4}$ between males and females. In addition, a statistically significant difference was found in the $\mathrm{TC}$ and $\mathrm{H}$ values between males and females. Compared to males, the female spinous process was shorter, thinner, and lower.

\section{Relevance of gender for each parameter}

According to Hinkle et al. (12), a Pearson coefficient of 1.0-0.9 means very high relevance, 0.9-0.7 means high relevance, 0.7-0.5 means moderate relevance, 0.5-0.3 means low relevance, and less than 0.3 means no relevance. The relevance of each parameter to gender is shown in Table 1. The $L_{1-2}, L_{2-3}$, and $L_{3-4}$ of $D A$ were of moderate relevance in males, while $L_{4-5}$ and $L_{5}-S_{1}$ of DA were of low relevance in males $(P<0.05)$. The $L_{1-2}, L_{2-3}, L_{3-4}$, $L_{4-5}$, and $L_{5}-S_{1}$ of $D A$ were of low relevance in females $(P<0.05)$. Moreover, $L_{1-2}$ of $T I$ was of low relevance in males $(P<0.05)$. For other parameters, there was no relevance found to either males or females.

\section{Design of the interspinous stabilization device}

Based on the anatomical parameters of the lumbar spine spinous processes obtained in this study, we proposed an $\mathrm{H}$-shaped coronal plane (posterior view, Figure 3) for an interspinous stabilization device for Chinese patients. Two grooves were located at the upper and lower ends of the spinous process, the width of the inferior groove (WIG) and the superior groove (WSG) matched with two adjacent spinous processes. This device has a kidney shape when viewed laterally (Figure 3 ). The sagittal diameter (SD) is a little smaller than the length of the spinous process, around $25 \mathrm{~mm}$, the central height $(\mathrm{CH})$ ranges from 3 to $13 \mathrm{~mm}$, the wing height is about $30-40 \mathrm{~mm}$, and the WSG is about

Table 1. Relevance of each parameter with gender.

\begin{tabular}{lccccrrrr}
\hline Location & Gender & DB & DA & H & TS & TC & TI \\
\hline $\mathrm{L}_{1-2}$ & Male & 0.211 & 0.532 & 0.176 & -0.192 & -0.141 & 0.336 \\
& Female & -0.180 & 0.348 & 0.261 & -0.239 & -0.274 & -0.074 \\
$\mathrm{~L}_{2-3}$ & Male & 0.060 & 0.635 & -0.075 & -0.028 & -0.046 & -0.037 \\
& Female & -0.280 & 0.306 & 0.141 & -0.149 & 0.001 & 0.029 \\
$\mathrm{~L}_{3-4}$ & Male & -0.006 & 0.670 & 0.131 & 0.047 & -0.025 & 0.016 \\
& Female & -0.014 & 0.215 & 0.276 & -0.130 & 0.098 & 0.181 \\
$\mathrm{~L}_{4-5}$ & Male & -0.010 & 0.338 & 0.040 & 0.116 & 0.264 & -0.022 \\
& Female & 0.001 & 0.398 & 0.121 & -0.075 & 0.047 & 0.148 \\
$\mathrm{~L}_{5}-\mathrm{S}_{1}$ & Male & 0.136 & 0.363 & 0.143 & -0.366 & -0.026 & -0.366 \\
& Female & 0.137 & 0.319 & -0.008 & 0.254 & 0.254 & 0.034 \\
\hline
\end{tabular}

DB: distance between two adjacent spinous processes; DA: distance across two adjacent spinous processes; $\mathrm{H}$ : height of the spinous processes; TS: thickness of the superior margin of the spinous processes; TC: thickness of the central spinous processes; TI: thickness of the inferior margin of the spinous processes. Relevance: 1.0-0.9: very high relevance; 0.9-0.7: high relevance; 0.7-0.5: moderate relevance; 0.5-0.3: low relevance; $<0.3$ : no relevance. 

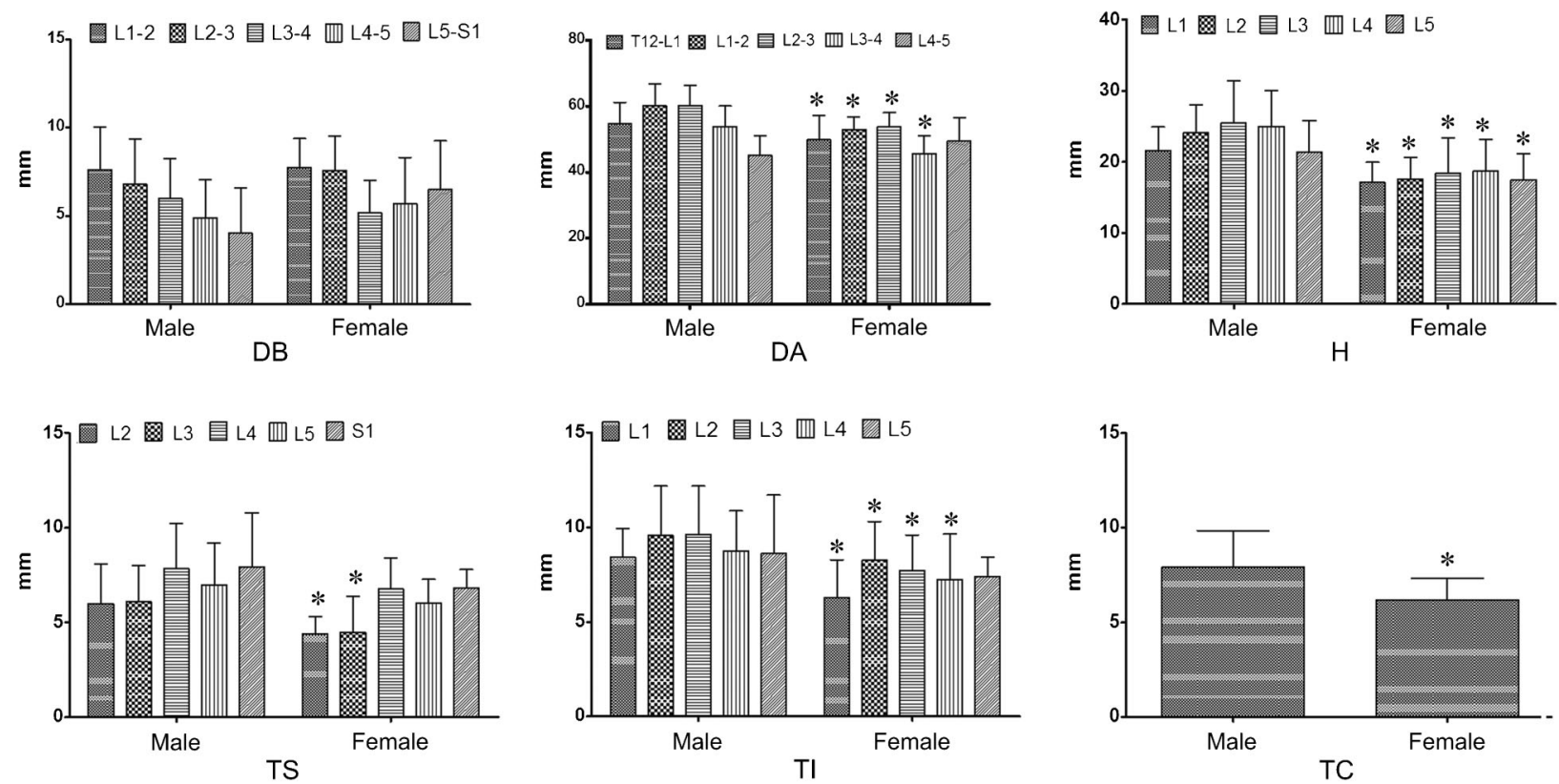

Figure 2. Comparison of each parameter (DB, DA, H, TS, TI, and TC) between males and females. DB: distance between two adjacent spinous processes; DA: distance across two adjacent spinous processes; $\mathrm{H}$ : height of the spinous processes; TS: thickness of the superior margin of the spinous processes; TI: thickness of the inferior margin of the spinous processes; TC: thickness of the central spinous processes. ${ }^{*} \mathrm{P}<0.05$ female vs male (one-way ANOVA).

5-10 mm, whereas the WIG is 3-6 mm less than that of the WSG.

\section{Discussion}

Until recently, numerous interspinous implants have been introduced and have shown favorable outcomes in the treatment of degenerative disc disease, herniated nucleus pulposus, lumbar spinal stenosis, lumbar instability, and degenerative spondylolisthesis $(8,9,13-15)$. Nevertheless, complications still occur in interspinous
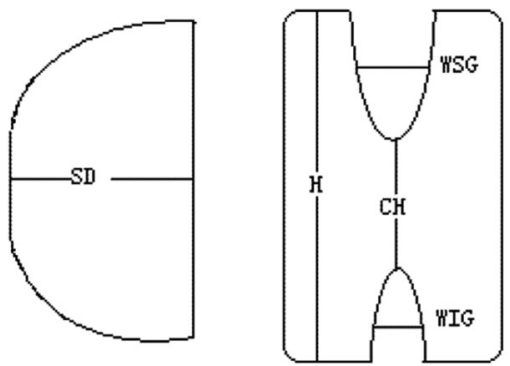

Lateral view

\section{Posterior view}

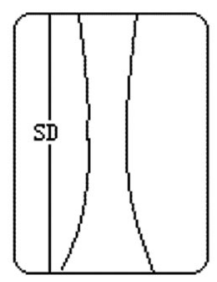

Top view
Figure 3. A proposed interspinous stabilization device for Chinese patients in lateral view, posterior view and top view. $\mathrm{SD}$ : sagittal diameter; $\mathrm{H}$ : height; $\mathrm{CH}$ : central height; WSG: width of the superior groove; WIG: width of the inferior groove. implants. Thus, selection of an optimal size is mandatory to avoid unwanted complications, and the size of the device should be carefully evaluated $(2,11)$. In the present work, we measured the anatomical parameters of the lumbar spinous processes in the Chinese population using 52 adult cadavers. Based on the anatomical parameters of the lumbar spinous processes obtained in this study, we proposed a design for an interspinous stabilization device for the Chinese population.

Data obtained in each group were of normal distribution and homogeneity of variance, which could reflect a common Chinese population. According to the measurement data, several characteristics were found: 1) the $D B$ decreased gradually from $L_{1-2}$ to $L_{5}-S_{1} ; 2$ ) the $D A$ increased from $T_{12}-L_{1}$ to $L_{2-3}$, and then decreased from $L_{2-3}$ to $L_{4-5} ; 3$ ) the largest $H$ in males was noted at $L_{3}$, whereas it was noted at $\mathrm{L}_{4}$ in females; and 4) the TS of the adjacent spinous process was lower than that of the TI. The middle sections of the DA, $\mathrm{H}$, and TI were found to be larger than those of the upper and lower ends. Compared to males, the female spinous processes were shorter, thinner, and lower. The difference in size of the lumbar spinous processes between males and females probably reflects the difference in average physical size between the genders (16). Ihm et al. (2) investigated the morphometry of the spinous process for interspinous device implantation in Korean patients. They found that the interspinous distance decreased from $L_{1-2}$ to $L_{5}-S_{1}$, and the height increased from $L_{1}$ to $L_{2}$ and gradually decreased below $L_{3}$. 
The tendency for variation of the interspinous distance was similar to the results obtained in our research, but the results for height were not similar. The largest value for height obtained in our study was at $L_{3}$ and gradually decreased below $L_{3}$.

Based on the results of this study for the anatomical parameters of the lumbar spinous processes, an $\mathrm{H}$-shaped coronal plane (posterior view) was proposed for the design of an interspinous stabilization device for the Chinese population. As described previously, implant subsidence is a naturally occurring process that is observed during aging and after spine surgery $(16,17)$. A device can migrate if a loosely fitted implant is used when considering future subsidence (11). Dynamic implants allow normal (natural) subsidence to occur, which can stabilize the spine effectively by preventing translation, rotation, and angular deformation (17). The effect of aging and subsidence should be considered carefully when using interspinous implants.

\section{References}

1. Siebert E, Pruss H, Klingebiel R, Failli V, Einhaupl KM, Schwab JM. Lumbar spinal stenosis: syndrome, diagnostics and treatment. Nat Rev Neurol 2009; 5: 392-403, doi: 10.1038/nrneurol.2009.90.

2. Ihm EH, Han IB, Shin DA, Kim TG, Huh R, Chung SS. Spinous process morphometry for interspinous device implantation in Korean patients. World Neurosurg 2013; 79: 172-176, doi: 10.1016/j.wneu.2011.04.027.

3. Jolles BM, Porchet F, Theumann N. Surgical treatment of lumbar spinal stenosis. Five-year follow-up. J Bone Joint Surg Br 2001; 83: 949-953, doi: 10.1302/0301-620X.83B7.11722.

4. Postacchini F, Cinotti G, Gumina S, Perugia D. Long-term results of surgery in lumbar stenosis. 8-year review of 64 patients. Acta Orthop Scand Suppl 1993; 251: 78-80, doi: 10.3109/17453679309160127.

5. Schlegel JD, Smith JA, Schleusener RL. Lumbar motion segment pathology adjacent to thoracolumbar, lumbar, and lumbosacral fusions. Spine 1996; 21: 970-981, doi: 10.1097/ 00007632-199604150-00013.

6. Schmoelz W, Huber JF, Nydegger T, Dipl I, Claes L, Wilke HJ. Dynamic stabilization of the lumbar spine and its effects on adjacent segments: an in vitro experiment. J Spinal Disord Tech 2003; 16: 418-423, doi: 10.1097/00024720200308000-00015.

7. Tsai KJ, Murakami H, Lowery GL, Hutton WC. A biomechanical evaluation of an interspinous device (Coflex) used to stabilize the lumbar spine. J Surg Orthop Adv 2006; 15: 167-172.

8. Shim CS, Park SW, Lee SH, Lim TJ, Chun K, Kim DH. Biomechanical evaluation of an interspinous stabilizing device, Locker. Spine 2008; 33: E820-E827, doi: 10.1097/ BRS.0b013e3181894fb1.

9. Bono CM, Vaccaro AR. Interspinous process devices in the lumbar spine. J Spinal Disord Tech 2007; 20: 255-261, doi:
We acknowledge that there are several limitations to this study. The study may not capture all the anatomical variations because of the small sample size. A larger sample size may result in narrower standard deviations. This study was performed on cadaver specimens. A larger sample from live patients would be better. Future work is needed for morphometric studies of the human lumbar spine by computed tomography for Chinese populations. In conclusion, despite these limitations, our study still has value in terms of reporting on the anatomical parameters of the lumbar spinous process, for the design of an interspinous stabilization device for the Chinese population and by offering an anatomical basis for clinical applications.

\section{Acknowledgments}

We wish to express our warm thanks to the donors of the cadavers.

10.1097/BSD.0b013e3180331352.

10. Barbagallo GM, Olindo G, Corbino L, Albanese V. Analysis of complications in patients treated with the X-Stop Interspinous Process Decompression System: proposal for a novel anatomic scoring system for patient selection and review of the literature. Neurosurgery 2009; 65: 111-119, doi: 10.1227/01.NEU.0000346254.07116.31.

11. Bowers C, Amini A, Dailey AT, Schmidt MH. Dynamic interspinous process stabilization: review of complications associated with the X-Stop device. Neurosurg Focus 2010; 28: E8, doi: 10.3171/2010.3.FOCUS1047.

12. Hinkle DE, Wiersma W, Jurs SG. Applied statistics for the behavioral sciences. Boston: Houghton Mifflin; 2003.

13. Chiu JC. Interspinous process decompression (IPD) system (X-STOP) for the treatment of lumbar spinal stenosis. Surg Technol Int 2006; 15: 265-275.

14. Mariottini A, Pieri S, Giachi S, Carangelo B, Zalaffi A, Muzii FV, et al. Preliminary results of a soft novel lumbar intervertebral prothesis (DIAM) in the degenerative spinal pathology. Acta Neurochir Suppl 2005; 92: 129-131, doi: 10.1007/3-21127458-8_28.

15. Yano S, Hida K, Seki T, Aoyama T, Akino M, Iwasaki Y. A new ceramic interspinous process spacer for lumbar spinal canal stenosis. Neurosurgery 2008; 63: ONS108ONS113, doi: 10.1227/01.NEU.0000310693.86660.D3.

16. Aylott CE, Puna R, Robertson PA, Walker C. Spinous process morphology: the effect of ageing through adulthood on spinous process size and relationship to sagittal alignment. Eur Spine J 2012; 21: 1007-1012, doi: 10.1007/ s00586-011-2029-6.

17. Steinmetz MP, Benzel EC, Apfelbaum RI. Axially dynamic implants for stabilization of the cervical spine. Neurosurgery 2006; 59: ONS378-ONS388, doi: 10.1227/01.NEU.0000 233901.53692.E1. 